11. Ataseven B, Lederer B, Blohmer JU, Denkert C, Gerber B, Heil J, et al. Impact of multifocal or multicentric disease on surgery and locoregional, distant and overall survival of 6,134 breast cancer patients treated with neoadjuvant chemotherapy. Ann Surg Oncol. 2015;22(4):1118-27.

12. Santoro S, Loreti A, Cavaliere F, Costarelli L, La Pinta M, Manna E, et al. Neoadjuvant chemotherapy is not a contraindication for nipple sparing mastectomy. Breast. 2015;24(5):661-66.

13. El Hage Chehade H, Headon H, El Tokhy O, Heeney J, Kasem A, Mokbel K. Is sentinel lymph node biopsy a viable alternative to complete axillary dissection following neoadjuvant chemotherapy in women with node-positive breast cancer at diagnosis? An updated meta-analysis involving 3,398 patients. Am J Surg. 2016;212(5):969-81. doi: 10.1016/j.amjsurg.2016.07.018.

14. Семиглазов ВФ, Семиглазов ВВ, Николаев КС, Комяхов АВ, Семиглазова ТЮ, Палтуев РМ. Деэскалация и эскалация лечения пациентов с HER2-позитивным раком молочной железы. Фарматека. 2017; 17:8-13.

15. Francis PA, Regan MM, Fleming GF, Lang I, Ciruelos E, Bellet $\mathrm{M}$, et al. Adjuvant ovarian suppression in premenopausal breast cancer. $N$ Engl J Med. 2015;372(5):436-46. doi: 10.1056/NEJMoa1412379.

16. Pagani O, Regan MM, Walley BA, Fleming GF, Colleoni M, Lang I, et al. Adjuvant exemestane with ovarian suppression in premenopausal breast cancer. $N$ Eng Med. 2014;371(2):107-18. doi: 10.1056/NEJMoa1404037.

17. Burstein HJ, Temin S, Anderson H, Buchholz TA, Davidson NE, Gelmon K.E, et al. Adjuvant endocrine therapy for women with hormone receptor-positive breast cancer: American Society of clinical oncology clinical practice guideline focused update. J Clin Oncol. 2014;32(21):2255-69. doi: 10.1200/JCO.2013.54.2258.

\section{REFERENSES}

1. Nelyubina LA. Rak molochnoy zhelezyi: strategii otsenki i snizheniya riska zabolevaniya. Vestnik TGU. 2014;19(6):1919-27. (in Russ.)

2. Curigliano G, Burstein HJ, Winer EP, Gnant M, Dubsky P, Loibl S, et al. De-escalating and escalating treatments for early-stage breast cancer: the St. Gallen International Expert Consensus Conference on the Primary Therapy of Early Breast Cancer 2017. Ann of Oncol. 2017;28(8):1700-12. doi:10.1093/annonc/mdx308.

3. Wapnir IL, Dignam JJ, Fisher B, Mamounas EP, Anderson SJ, Julian T.B, et al. Long-term outcome of invasive ipsilateral breast tumor recurrences after lumpectomy in NSABP-17 and B-24 randomized clinical trials for DCIS. $J$ Natl Cancer Inst. 2011;103(6):478-88. doi: 10.1093/jnci/djr027.

4. Morrow M, Van Zee KJ, Solin LJ, Houssami N, ChavezMacGregor M, Harris J.R, et al. Society of Surgical Oncology-American Society for Radiation Oncology-American Society of Clinical Oncology Consensus Guideline on margins for breast-conserving surgery with whole-breast irradiation in ductal carcinoma in situ. Pract Radiat. Oncol. 2016;6(5):287-95. doi: 10.1016/j.prro.2016.06.011.

5. Forbes JF, Sestak I, Howell A, Bonanni B, Bundred N, Levy $\mathrm{C}$, et al. Anastrozole versus tamoxifen for the prevention of locoregional and contralateral breast cancer in postmenopausal women with locally excised ductal carcinoma in situ (IBIS-II DCIS): a doubleblind, randomised controlled trial. Lancet. 2016;387(10021):866-73. doi: 10.1016/S0140-6736(15)01129-0.
6. Semiglazov VF. Itogi 15-y mezhdunarodnoy konferentsii po raku molochnoy zhelezyi (San-Gallen, 2017). Eskalatsiya deeskalatsiya lecheniya Elektronnyiy resurs]. Medvestnik. Portal rossiyskogo vracha. [data obrascheniya: 2018 May 03]. https://www.medvestnik.ru/content (in Russ.).

7. Moran MS, Schnitt SJ, Giuliano AE, Harris JR, Khan SA, Horton J, et al. Society of Surgicall Oncology-American Society for Radiation Oncology consensus guideline on margins for breastconserving surgery with whole-breast irradiation in stages I and II invasive breast cancer. J Clin Oncol.. 2014;32:1507-15.

8. Letyagin VP, Vyisotskaya IV, Grigoreva TA. Sovremennyie podhodyi $\mathrm{k}$ lecheniyu bolnyih pervichno-operabelnyim rakom molochnoy. Ros Onkol. ZHurn. 2013;6:39-47. (in Russ.)

9. De La Cruz L, Moody AM, Tappy EE, Blankenship SA, Hecht EM. Overall survival, disease-free survival, local recurrence, and nipple-areolar recurrence in the setting of nipple-sparing mastectomy: a meta-analysis and systematic review Ann Surg Oncol. 2015;22(10):3241-49. doi: 10.1245/s10434-015-4739-1.

10. Giuliano AE, Hunt KK, Ballman KV, Beitsch PD, Whitworth PW, Blumencranz PW, et al. Axillary dissection vs no axillary dissection in women with invasive breast cancer and sentinel node metastasis: a randomized clinical trial. JAMA. 2011;305(6):569-75. doi: 10.1001/jama.2011.90.

11. Ataseven B, Lederer B, Bilohmer JU, Denkert C, Gerber B, Heil $\mathrm{J}$, et al. Impact of multifocal or multicentric disease on surgery and locoregional, distant and overall survival of 6,134 breast cance patients treated with neoadjuvant chemotherapy. Ann Surg Oncol. 2015;22(4):1118-27.

12. Santoro S, Loreti A, Cavaliere F, Costarelli L, La Pinta M, Manna E, et al. Neoadjuvant chemotherapy is not a contraindication for nipple sparing mastectomy. Brealst. 2015;24(5):661-66.

13. El Hage Chehade H, Headon H, El Tokhy O, Heeney J, Kasem A, Mokbel K. Is sentinel lymph node biopsy a viable alternative to complete axillary dissection following neoadjuvant chemotherapy in women with node-positive breast cancer at diagnosis? An updated meta-analysis involving 3,398 patients. Am J Surg. 2016;212(5):969-81. doi: 10.1016/j.amjsurg.2016.07.018.

14. Semiglazov VF, Semiglazov VV, Nikolaev KS, Komyahov AV, Semiglazova TYu, Paltuev RM. Deeskalatsiya i eskalatsiya lecheniya patsientov s HER2-pozitivnyim rakom molochnoy zhelezyi. Farmateka. 2017;17:8-13. (in Russ.)

15. Francis PA, Regan MM, Fleming GF, Lang I, Ciruelos E, Bellet $\mathrm{M}$, et al. Adjuvant ovarian suppression in premenopausal breast cancer. $N$ Engl $J$ Med. 2015;372(5):436-46. doi 10.1056/NEJMoa1412379.

16. Pagani O, Regan MM, Walley BA, Fleming GF, Colleoni M, Lang I, et al. Adjuvant exemesitane with ovarian suppression in premenopausal breast cancer. $N$ Engl J Med. 2014;371(2):107-18. doi: 10.1056/NEJMoa1404037.

17. Burstein HJ, Temin S, Anderson H, Buchholz TA, Davidson NE, Gelmon K.E, et al. Adjuvant endocrine therapy for women with hormone receptor-positive breast cancer: American Society of clinical oncology clinical practice guideline focused update. J Clin Oncol. 2014:32(21):2255-69. doi: 10.1200/JCO.2013.54.2258.

Поступила 04.05.2018

УДК 616.75-007.17-076

МОРФОЛОГИЧЕСКАЯ ОЦЕНКА ВЫРАЖЕННОСТИ ДИСТРОФИЧЕСКИХ ИЗМЕНЕНИЙ ПОДВЗДОШНО-ПОЯСНИЧНЫХ, КРЕСТЦОВО-ПОДВЗДОШНЫХ И КРЕСТЦОВО-БУГОРНЫХ СВЯЗОК: ВОЗМОЖНОСТИ БИОПСИИ

\author{
А. М. Юрковский ${ }^{1}$, С. Л. Ачинович ${ }^{2}$,. В. Назаренко \\ ${ }^{1}$ Учреждение образования \\ «Гомельский государственный медицинский университет», \\ г. Гомель, Республика Беларусь \\ ${ }^{2}$ Учреждение \\ «Гомельский областной клинический онкологический диспансер», \\ г. Гомель, Республика Беларусь
}

Цель: определить возможности использования диагностической пункции для оценки выраженности дистрофических изменений подвздошно-поясничной, крестцово-подвздошной и крестцово-бугорной связок. 
Материал и методы. Проведено сравнение результатов полуколичественной морфологической оценки (шкала Bonar) секционного материала с материалом, полученным при биопсии подвздошно-поясничных, крестцово-подвздошных и крестцово-бугорных связок от 15 трупов (средний возраст умерших 64,5 $\pm 6,5$ года).

Результаты. Выявлены различия в оценках выраженности дистрофических изменений при сравнении секционных данных с данными биопсии в части, касающейся оценки фибробластов, приводящими к занижению итоговой оценки по шкале Bonar на 1 балл.

Заключение. Биопсийный материал может использоваться для ориентировочной оценки выраженности дистрофических изменений по критериям «межуточное вещество», «коллагеновые волокна» и «васкуляризация». По критерию «клетки фибробластического дифферона» оценка может оказаться заниженной на 1 балл, что необходимо учитывать при интерпретации данных.

Ключевые слова: подвздошно-поясничные, крестцово-подвздошные и крестцово-бугорные связки, биопсия, гистопатологические изменения.

\title{
MORPHOLOGICAL EVALUATION OF INTENSITY OF DYSTROPHIC CHANGES IN ILIOLUMBAR, SACRO-ILIAC AND SACROTUBERAL LIGAMENTS: POTENTIAL FOR BIOPSY
}

\author{
A. M. Yurkovskiy ${ }^{1}$, S. L. Achinovich ${ }^{2}$, I. V. Nazarenko ${ }^{1}$ \\ ${ }^{1}$ Gomel State Medical University, Gomel, Republic of Belarus \\ ${ }^{2}$ Gomel Regional Clinical Oncology Center, Gomel, Republic of Belarus
}

Obiective: to evaluate the potential of the use of a diagnostic puncture for the analysis of intensity of dystrophic changes in ilio-lumbar, sacro-iliac, and sacro-tuberal ligaments.

Material and methods. The work presents the comparison of the results of the semi-quantitative morphological evaluation (Bonar scale) of the sectional material and the material obtained during biopsy of the iliac-lumbar, sacroiliac and sacro-ligamentous ligaments from 15 corpses (the average age at death was $64.5 \pm 6.5$ ).

Results. The comparison of the sectional data and biopsy data detected differences in the evaluations of intensity of dystrophic changes in the part concerning the evaluation of fibroblasts that lead to a decreased final Bonar score by 1 point.

Conclusion. Biopsy material can be used for approximate evaluation of intensity of dystrophic changes according to the criteria «interstitial substance», «collagenous fibers» and «vascularization». The evaluation according to the criterion «fibroblastic programed differentiation cells» can be decreased by 1 point, which should be taken in account in the data interpretation.

Key words: iliolumbar ligament, long dorsal sacroiliac ligament, sacrotuberous ligament, biopsy, histopathologic changes.

\section{Введение}

Возникновение синдрома боли в нижней части спины (синдроме БНЧС) связывают с функциональными и дистрофическими изменениями опорно-двигательного аппарата. Структурами, потенциально способными в случае повреждения инициировать боль, являются связки пояснично-крестцового отдела позвоночника, в частности, подвздошно-поясничные (ППС), задние длинные крестцово-подвздошные (ЗДКПС) и крестцово-бугорные (КБС) связки [1-3]. Диагностика патологии указанных связок основывается на выявлении локальной болезненности (при пальпации и/или провокационных тестах) $[3,7,8]$, структурных изменений (на диагностических изображениях) $[4-6,7,8]$ и положительном эффекте (уменьшении интенсивности боли) от введения в область указанных связок раствора анестетика $[7,9]$.

Насколько специфичны для лигаментиндуцированного синдрома БНЧС перечисленные критерии, неизвестно [7, 8], поскольку не разработаны способы прижизненной морфологической верификации изменений, выяв- ляемых методами визуализации в ППС, ЗДКПС и КБС при указанной патологии.

Предложенные ранее методики оценки гистопатологических изменений ППС, ЗДКПС и КБС (оценка по шкале Bonar и/или по морфометрическим показателям клеток фибробластического дифферона), с одной стороны, хорошо зарекомендовали себя при секционных исследованиях [4-6, 10], однако с другой - опыт их применения для оценки биопсийного материала, полученного из указанных связок, отсутствует. Во всяком случае в ресурсах PubMed и e-Library такой информации не найдено.

\section{Цель работы}

Определить возможности использования диагностической пункции для оценки выраженности дистрофических изменений ППС, ЗДКПС и КБС.

\section{Материал и методы}

Для достижения поставленной цели была проведена оценка выраженности дистрофических изменений в материале, полученном из одних и тех же связок при биопсии и во время секции. 
Для этого на первом этапе была выполнена биопсия и аутопсия ППС, ЗДКПС и КБС от 15 трупов (возрастной диапазон умерших 48-77 лет): 8 мужчин (средний возраст $62,0 \pm 10,1$ года) и 7 женщин (средний возраст 67,4 $\pm 5,9$ года).

На втором этапе проводилось приготовление гистологических препаратов: осуществлялась стандартная процедура парафиновой проводки; приготавливались срезы толщиной 4 мкм, которые затем окрашивались гематоксилинэозином, проводилась ШИК-реакция, окраска толуидиновым синим и по Ван Гизону. Микроскопия гистологических препаратов проводилась в проходящем свете на большом увеличении $(\times 400)$.

Оценка патогистологических изменений материала проводилась двумя специалистами независимо друг от друга по следующим критериям: клетки фибробластического дифферона (0 баллов - удлиненная форма ядра без отчетливой визуализации цитоплазмы; 1 балл форма ядра приобретает яйцевидную конфигурацию, но без отчетливой визуализации цитоплазмы; 2 балла - ядро округляется, немного увеличивается, визуализируется малое количество цитоплазмы; 3 балла - ядро округлое, большое, обильная цитоплазма с формирующимися углублениями); межуточное вещество (0 баллов - отсутствие окрашивания межуточного вещества; 1 балл - окрашивающийся муцин между волокнами; 2 балла - окрашивающийся муцин между волокнами с нарушением дифференцировки коллагеновых волокон; 3 балла - муцин повсюду, с малозаметным прокрашиванием волокон коллагена); коллагеновые волокна (0 баллов - отсутствие разделения волокон; 1 балл - разделение отдельных волокон с сохранением четкости границ; 2 балла - разделение волокон с утратой четкости границ, увеличение межуточного вещества; 3 балла - разделение волокон колла- гена с полной потерей архитектоники связки); васкуляризация (0 баллов - кровеносные сосуды, расположенные между волокнами, не визуализируются; 1 балл - капилляры в количестве до одного в 10 полях зрения; 2 балла 1-2 капилляра в 10 полях зрения; 3 балла более 2 капилляров в 10 полях зрения) [10].

Для вычисления морфометрических показателей клеток фибробластического дифферона изображения микропрепаратов фиксировались с помощью микроскопа Olympus CX 41 с фотокамерой SC-20 в 6 полях зрения (площадь исследуемых полей зрения составляла 159490 мкм² $^{2}$ при увеличении $\times 400$ ). Морфометрические расчеты проводились при помощи анализатора изображений WCIF ImageJ [10].

Использовались следующие методы статистической обработки: оценка нормальности распределения признаков проводилась с применением критерия Шапиро-Уилка; в случае распределения количественных показателей, отличного от нормального, данные представлялись в виде медианы 25-го и 75-го перцентилей (Me $25 \%-75 \%$ ), при нормальном распределении признаков - в виде среднего арифметического и стандартного отклонения среднего арифметического $(\mathrm{M} \pm \mathrm{SD})$. Для сравнения морфометрических параметров контрлатеральных связок использовался T-test.

\section{Результаты и обсуждение}

Дистрофические изменения разной степени выраженности были выявлены во всех образцах ППС, ЗДКПС и КБС. Статистически значимых различий между выраженностью дистрофических изменений контрлатеральных ППС, ЗДКПС И КБС выявлено не было.

Итоговые оценки по шкале Bonar, полученные при анализе секционного материала, в большинстве случаевઃ оказались на 1 балл выше оценок, полученных при анализе биопсийного материала (рисунок 1).

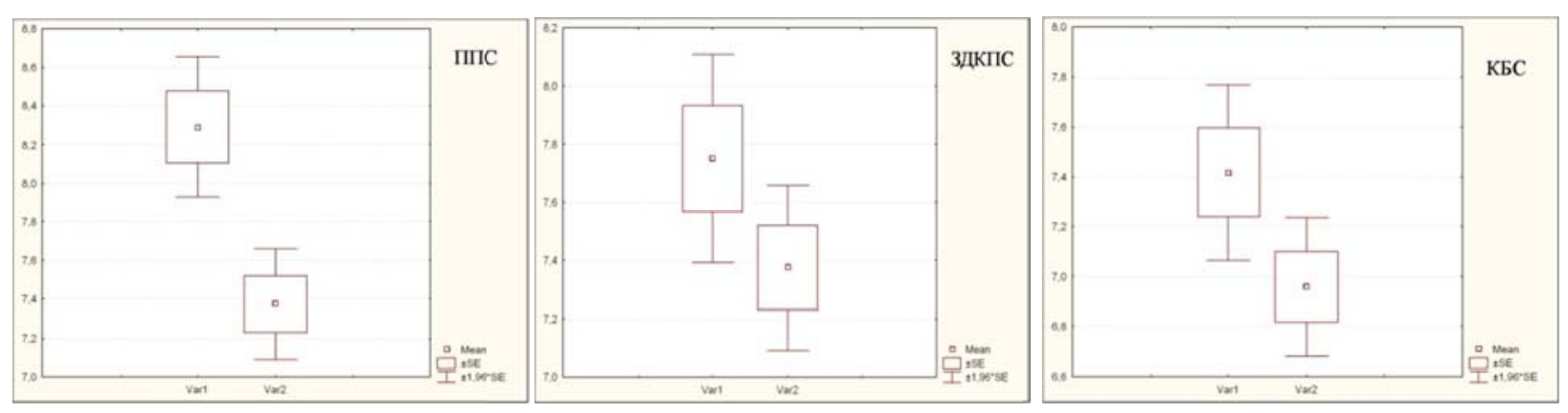

Рисунок 1 - Сопоставление итоговых оценок по шкале Вonar ППС, ЗДКПС и КБС соответственно: Var. 1 - биопсийный материал; Var. 2 - секционный материал $(p=0,02 ; p=0,02 ; p=0,05$ соответственно)

Что касается остальных критериев, то значимых различий между секционными данными и данными, полученными при оценке биопсийного материала, отмечено не было: по кри- 
териям «межуточное вещество», «коллагеновые волокна» и «васкуляризация» результаты оказались сопоставимыми.

Исходя из того, что количество биопсийного материала может оказаться весьма незначительным, была оценена перспектива использования показателя ядерно-цитоплазматического отношения (ЯЦО) для ориентировочной ощенки выраженности дистрофических изменений ППС, ЗДКПС и КБС [10]. В итоге оказалось, что по этому критерию также есть различия: средний показатель при оценке секционного материала был значимо выше, чем при оценке биоптата: $0,49 \pm 0,05$ и $0,43 \pm 0,0$ соответственно $(\mathrm{p}=$ 0,0004); кроме того, количество выбросов показателей ЯЦО при оценке биопсийного материала было выше по сравнению с секционными данными (график рассеяния представлен на рисунке 2). Этому соответствуют и результаты корреляционного анализа: коэффициент корреляции между итоговыми оценками по шкале Bonar и показателями ЯЦО при оценке материала, полученного во время секции, оказался более высоким, чем при биопсии: $\mathrm{R}=0,88(\mathrm{p}=0,00001)$ и $\mathrm{R}=0,48$ ( $\mathrm{p}=0,05)$ соответственно. Та же закономерность была отмечена и при оценке материала, полученного из ЗДКПС и КБС.

Как следует из вышеприведенных данных, различия в величине итоговых показателей по шкале Bonar являются следствием не точной оценки по критерию «клетки фибробластического дифферона» (рисунок 3 ).

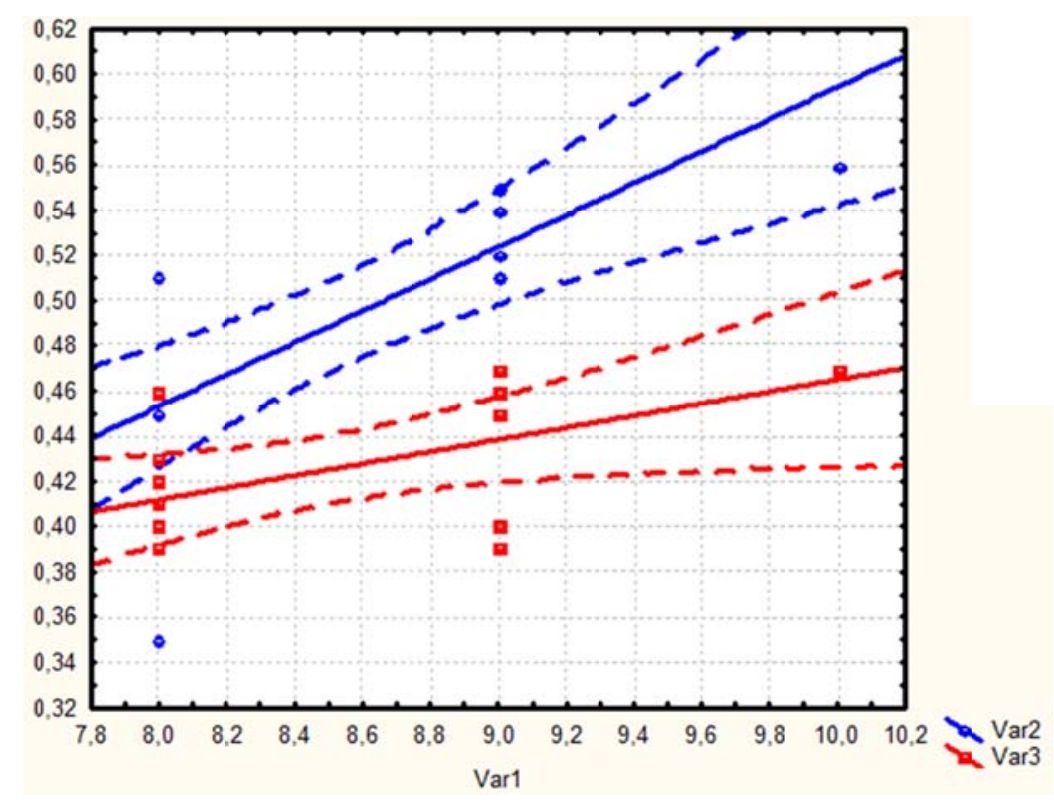

Рисунок 2 - График рассеяния показателей ядерно-цитоплазматического отношения соотносительно итоговой оценке по шкале Воnar (без учета гендерной принадлежности материала) на примере ППС:

Var. 1 - итоговая оценка по шкале Bonar; Var. 2 - ЯЦО по результатам оценки биопсийного материала; Var. 3 - ЯЦО по результатам оценки секционного материала; пунктирная линия - 95 \% доверительная область
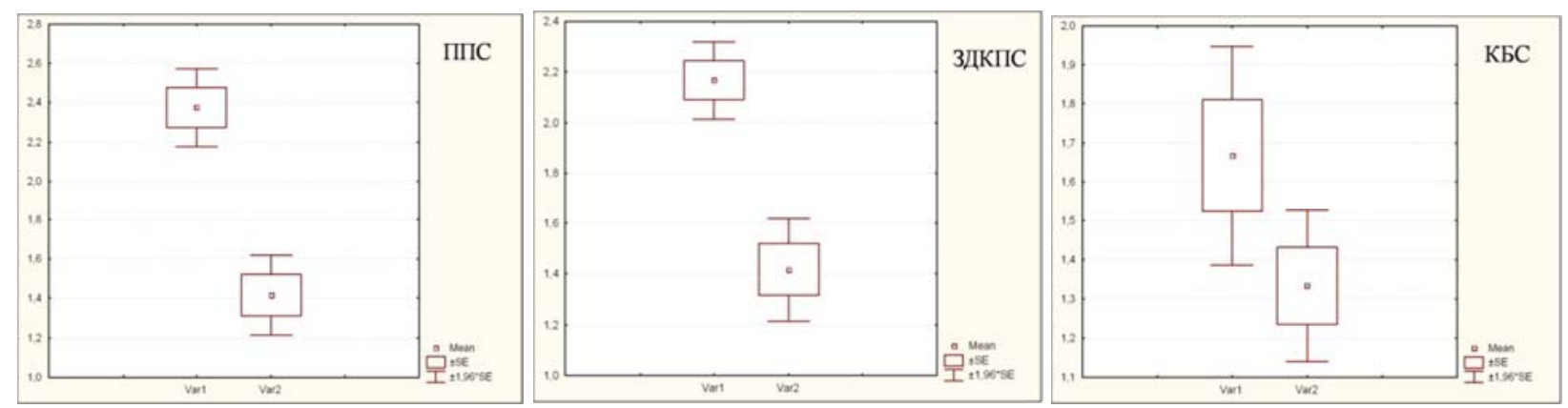

Рисунок 3 - Сопоставление оценок по критерию «клетки фибробластического дифферона» ППС, ЗДКПС и КБС соответственно: Var. 1 - секционный материал; Var. 2 - биопсийный материал $(p=0,00001 ; p=0,00001 ;, p=0,06$ соответственно)

Вероятнее всего неточность оценки обусловлена тем, что красители гематоксилин и эозин не совсем подходят для окраски препа- ратов, состоящих из оформленной плотной волокнистой соединительной ткани, поскольку цитоплазма клеток и вюлокна коллагена при 
этой методике окрашиваются почти одинаково, а потому на участках со спирально закрученными волокнами клетки, оказавшиеся в разных плоскостях, теряют четкость очертаний, что и приводит к ошибкам. Это нужно отметить в первую очередь. Во-вторых, оценке обычно подлежит материал, полученный из очень ограниченного участка связки, что в условиях неоднородности изменений, имеющихся в ППС, ЗДКПС и КБС [11], также может приводить к ошибкам, то есть либо к недооценке (например, при биопсии средней трети связок), либо к переоценке (например, при биопсии латеральной трети ППС, проксимальной трети ЗДКПС и дистальной трети КБС) выраженности изменений.

Таким образом, имеются определенные сложности с использованием биопсии для оценки выраженности дистрофических изменений ППС, ЗДКПС и КБС. Однако в ситуации, когда других способов верификации изменений на диагностических изображениях не существует, биопсия остается единственным способом решить эту проблему. Все, что для этого нужно это учесть вышеприведенные обстоятельства при интерпретации результатов.

В случае же, если будет предложен новый способ окраски, обеспечивающий более четкую дифференцировку цитоплазмы на фоне волокон коллагена, вполне возможно, что оценки по критерию «клетки фибробластического дифферона» станут более точными.

\section{Выводы}

1. Биопсийный материал может использоваться для ориентировочной оценки выраженности дистрофических изменений ППС, ЗДКПС и КБС по критериям «межуточное вещество», «коллагеновые волокна» и «васкуляризация», поскольку по этим критериям вероятность несоответствия с секционными данными минимальная;

2. По критерию «клетки фибробластического дифферона» оценка биопсийного материала с высокой вероятностью окажется ниже секционных данных на 1 балл, поэтому данное обстоятельство необходимо учитывать при интерпретации итогового показателя.

\section{ЛИТЕРАТУРА}

1. Юрковский АМ. Подвздошно-поясничная связка: анатомический базис для лучевого диагноста. Проблемы здоровья и экологии. 2010,4:84-89.

2. Юрковский АМ, Ачинович СЛ, Латышева ВЯ. Связки, ассоциированные с крестцово-подвздошным сочленением: анатомический базис для лучевого диагноста. Проблемыздоровьяиэкологии. 2013;4:67-72.

3. Reichert B, Stelzenmueller W. Palpation techniques: surface anatomy for physical therapists. NewYork: Thieme, 2011.P. 203-238.

4. Юрковский АМ, Ачинович СЛ, Кушнеров АИ. Возможности сонографии в оценке выраженности дистрофических изменений подвздошно-поясничной связки: сонографические и гистологические сопоставления (invitro). Военная медицина. 2014;4:66-69.
5. Михайлов АН, Юрковский АМ, Ачинович СЛ. Возможности сонографии в оценке выраженности дистрофических изменений задней длинной крестцово-подвздошной связки: сонографические и гистологические сопоставления (in vitro). Известия Наииональной академии наук Беларуси (серия медищинских наук). 2014;4:9-13.

6. Юрковский АМ, Аникеев ОИ, Ачинович СЛ. Дистрофические изменения крестцово-бугорной связки: сонографические и гистологические параллели (in vitro). Проблемы здоровья $u$ экологии. 2015;3:33-37.

7. Юрковский АМ. Экспертиза подвздошно-поясничной связки при синдроме боли в нижней части спины. Проблемы здоровья и экологии. 2011;3:106-110.

8. Назаренко ИВ. Лигаментоз задней длинной крестцовоподвздошной связки: нерешенные вопросы лучевой диагностики. Проблемы здоровья и экологии. 2017;2:4-7.

9. Юрковский АМ, Назаренко ИВ, Ачинович СЛ. Результаты диагностической блокады в области задней длинной крестцово-подвздошной связки под сонографическим контролем при синдроме боли в нижней части спины. Журнал ГрГМУ. 2017;5:516-20.

10. Юрковский АМ, Ачинович СЛ. Диагностическая значимость морфометрических показателей клеток фибробластического дифферона при оценке выраженности дистрофических изменений подвздошно-поясничных связок. Проблемы здоровья и экологии. 2014;1:102-107.

11. Юрковский АМ, Назаренко ИВ, Ачинович СЛ. Диагностическое значение различий в выраженности дистрофических изменений центральных и периферических участков подвздошно-поясничной, задней длинной крестцово-подвздошной и крестцово-бугорной связок. Проблемы здоровья и экологии. 2016;4:59-63.

\section{REFERENCES}

1. Jurkovskij AM. Podvzdoshno-pojasnichnaja svjazka: anatomicheskij bazis dlja luchevogo diagnosta. Problemy zdorov'ja $i$ jekologii. 2010,4:84-89. (in Russ.)

2. Jurkovskij AM, Achinovich SL, Latysheva VJa. Svjazki, associirovannye s krestcovo-podvzdoshnym sochleneniem: anatomicheskij bazis dlja luchevogo diagnosta. Problemyzdorov'jaijekologii. 2013;4:67-72. (in Russ.)

3. Reichert B, Stelzenmueller W. Palpation techniques: surface anatomy for physical therapists. NewYork: Thieme, 2011.P. 203238. (in Russ.)

4. Jurkovskij AM, Achinovich SL, Kushnerov AI. Vozmozhnosti sonografii $\mathrm{v}$ ocenke vyrazhennosti distroficheskih izmenenij podvzdoshno-pojasnichnoj svjazki: sonograficheskie gistologicheskie sopostavlenija (invitro). Voennaja medicina. 2014;4:66-69. (in Russ.)

5. Mihajlov AN, Jurkovskij AM, Achinovich SL. Vozmozhnost sonografii $v$ ocenke vyrazhennosti distroficheskih izmenenij zadnej dlinnoj krestcovo-podvzdoshnoj svjazki: sonograficheskie i gistologicheskie sopostavlenija (in vitro). Izvestija Nacional'noj akademii nauk Belarusi (serija medicinskih nauk). 2014;4:9-13. (in Russ.)

6. Jurkovskij AM, Anikeev OI, Achinovich SL. Distroficheskie izmenenija krestcovo-bugornoj svjazki: sonograficheskie i gistologicheskie paralleli (in vitro). Problemy zdorov'ja $i$ jekologii. 2015;3:33-37. (in Russ.)

7. Jurkovskij AM. Jekspertiza podvzdoshno-pojasnichnoj svjazki pri sindrome boli v nizhnej chasti spiny. Problemy zdorov'ja i jekologii. 2011;3:106-110. (in Russ.)

8. Nazarenko IV. Ligamentoz zadnej dlinnoj krestcovopodvzdoshnoj svjazki: nereshennye voprosy luchevoj diagnostiki. Problemy zdorov'ja i jekologii. 2017;2:4-7. (in Russ.)

9. Jurkovskij AM, Nazarenko IV, Achinovich SL. Rezul'taty diagnosticheskoj blokady $\mathrm{v}$ oblasti zadnej dlinnoj krestcovopodvzdoshnoj svjazki pod sonograficheskim kontrolem pri sindrome boli v nizhnej chasti spiny. Zhurnal GrGMU. 2017;5:516-20. (in Russ.)

10. Jurkovskij AM, Achinovich SL. Diagnosticheskaja znachimost' morfometricheskih pokazatelej kletok fibroblasticheskogo differona pri ocenke vyrazhennosti distroficheskih izmenenij podvzdoshno-pojasnichnyh svjazok. Problemy zdorov'ja i jekologii. 2014;1:102-107. (in Russ.)

11. Jurkovskij AM, Nazarenko IV, Achinovich SL. Diagnosticheskoe znachenie razlichij v vyrazhennosti distroficheskih izmenenij central'nyh i perifericheskih uchastkov podvzdoshno-pojasnichnoj, zadnej dlinnoj krestcovo-podvzdoshnoj i krestcovo-bugornoj svjazok. Problemy zdorov'ja i jekologii. 2016;4:59-63. (in Russ.) 